\title{
Economic Resources among the Urban Oldest-Old Females: Anthropological Study in Midnapore Municipal Town, West Bengal
}

\author{
Parikshit Chakraborty ${ }^{1 *}$ and Falguni Chakrabarty ${ }^{2}$ \\ ${ }^{1}$ Anthropological Survey of India, Ranchi Field Station, Ranchi - 834002, Jharkhand, India \\ ${ }^{2}$ Department of Anthropology, Vidyasagar University, Midnapore - 721102, West Bengal, India \\ "Corresponding author: parikshitchakraborty1@gmail.com
}

\begin{abstract}
Ageing is a natural fact in a life where social, cultural, economic and health issues attached to study of aging. The oldest old or Super Senior Citizen subpopulation in India is growing much faster than any other age group and due to their physical incapability they fall in peril situation which make them more dependent on others for their needs of financial support, medical assistance and social services etc. However, anthropological perspective on aging study is based on evolution of human aging as well as working incapability, economic dependency, sources of income and others. Therefore, authors of the present paper aim to highlight economic resources of the oldest-old female residing in different wards under Midnapore Municipal town of Paschim Medinipur district, West Bengal, India. The areas, which were explored, include some basic economic features such as different sources of financial support, sources of pension and amount of pension which deals with the economic resources of the Oldest Old. For the present paper data has been collected from about 500 oldest old female populations (using systematic random sampling table) living in urban areas of Medinipur Municipal Town. Therefore, the finding presented in this paper is that, the oldest old female under study area are seriously in economic disadvantageous position in many respects, which may be illustrated with the following facts: economically more dependent; most of them are non-worker; a very good number of them do not get/ receive any pension from any sources.
\end{abstract}

Keywords: Ageing, Super Senior Citizen, Anthropological perspective, Evolution of human aging, Economic Resources, Financial Support

Ageing has essential economic associations in terms of basic economic features such as housing and living arrangement, different sources of financial support which deals with the economic condition. Economic resources refers source of money income followed by earnings, private and public pensions. The system pensions have evolved over centuries to its present form. In India, there is a long history of pensions. A number of theories have been propounded which explain the social, economic and critical reasons for social security programs. The optimal distribution theory basically, is based on the idea that the elderly need assistance in terms of poverty alleviation and pension helps by transferring resources from younger generation to the older generation.

The oldest-old (80 years) constitute $7 \%$ of the world's 65 years-and-over population. However, the term "Oldest-old" generally used to refer to the population aged 85 and older, was coined for a 1984 session on this population at the annual meeting of the American Association for the Advancement of Science (AAAS). Therefore, limitations of survey data resulting from small sample sizes at the oldest ages, forced several studies of the oldest old to described the oldest-old as the ages 80 and older (Suzman \& Riley, 1985). 
Since the last decade or so, the Election Commission of India has started to publish separate voter list for the Indian citizens belonging to 80 years and above age and it was in the year 2011 the Department of Finance, Government of India categorized such population as 'Super Senior Citizen' for the purpose of income tax assessment (ENS Economic Bureau, The India Express, New Delhi, March 01, 2011).

In India majority of older persons face financial hardship in old age as most of them are not in a position to earn their livelihood. Their savings, if any, are not enough to meet their day to day, particularly the medical expenses. Many a times their family members and relatives exploit them due to their vulnerability. Financial status of older persons is directly linked with their financial independence. Ramamurti, Jamuna (1984) expresses economic, social and personal adjustments were found to be the important problems of adjustments in old age. The elderly can contribute, other than financially to build a common relationship by understanding the needs and limitations of the modern family in a different way Dhillon and Poduwal's Study (1992).

The Oldest old subpopulation is growing much faster than any other age group and because they are the most likely group to need medical and social services, it is necessary to investigate the demographic, socio-economic and health status of the oldest-old (Yi, Vaupel, Zhenyu, Chunyuan, Yuzhi; Population and Development Review, 28 (2: 251 - 273; June, 2002). In a few countries, notably the United States and a few European countries, efforts have been made to attract the attention of academics and policy makers to the circumstances of the oldest-old (Suzman, Willis and Manton 1992; Baltes and Mayer 1999; Veupal and Lundstrom 1994, Vaupal et al. 1998).

In India major aspects covered by the researchers on gerontology primarily centre around the economic crises, family environments and care, extra familial rehabilitation and living conditions under such rehabilitation, abuse, leisure and recreation, socio-psychological adjustment, health status etc. of the elderly living in different parts of India (Chakrabarty, 2003).

In recent decades, as the population has aged, aging has increasingly become a burning topic to address many disciplines and perspectives. Thus, studied of aging population is sensational in $21^{\text {st }}$ century in the disciplines like sociology, social-cultural anthropology and social gerontology to study age, aging, and the life course. The oldest old, persons aged 80 years or older, currently number 70 million and the majority of whom live in more developed states. However, India has $80,38,718$ populations of $80+$ out of which 20,22,345 live in urban areas (Census 2001).

M.Z. Khan's studies (1997) in the city of New Delhi entitled 'Elderly in Metropolis' only dealt with the demographic and socio-economic aspects of the elderly. But he did not focus anything about the health aspects of the elderly residing in New Delhi. Along with demographic assessment, some studies have indicated the implication of the ageing phenomenon through its conventional dependency ratios (Irudaya Rajan, 1989; 1992; Kumar, 1991). In many situations, it is also found that the rural elderly continue to work, though their number of working hours comes down with increasing age (Singh et al. 1987). Rajan (2001) explains the National Old Age Pension Scheme (NOAPS) was introduced on $15^{\text {th }}$ August 1995 under the National Social Assistance Scheme. Many states give the lowest pension amount of ₹ 60 per month, while the State of West Bengal Pays the highest amount of ₹ 300. Moreover, now-a-days West Bengal Old Age Pension Scheme assists of ₹ 750 per month.

However, economic anthropology attempts to explain human economic comportment and studies how human societies run through the material goods and services that make life possible. Thus, as scholars of anthropology, we thought that it is wise to consider the problems of the oldest-old from the economic perspectives. Therefore, in the present paper, as a matter of micro-level study, an attempt has been made to highlight the economic resources among the urban oldest old female since such study is very limited in India or may be almost absent in the field of social gerontological studies as well as aging studies in anthropology.

\section{MATERIALS AND METHODS}

The present study has been conducted among the oldest old (80 years and above) populations across both the sexes distributed over ten municipal wards under Midnapore Municipal town in the district of Paschim Medinipur, West Bengal, India. The ward 
numbers are namely ward no. 11 , ward no. 12 , ward no. 13 , ward no. 14 , ward no. 15 , ward no. 16 , ward no. 17, ward no. 18, ward no. 19 and ward no. 20.

For the purpose of locating and sampling the oldestold population residing in different municipal wards mentioned above the present researcher at the first stage downloaded the voter list of the Assembly Constituency no 236 uploaded in their official website by the Election Commission of India in the year 2015. This list, under its different part number, bears the name, age, sex and address of the voters residing in the villages under above referred ten municipal wards.

It appears from the said voter lists that there are altogether 547 'oldest old' female residing in the above referred villages municipal wards. However, for the present study the researchers selected 50 oldest-old female from each of the ten municipal wards respectively using Systematic random sampling table which formed the sample size of 500 respondents.

In case of sampling of respondents the provisions were made for one substitutes from each village so as to replace the same in case of the originally sampled respondent were not available, unwilling or physically unfit to respond during the field survey.

After the sampling of the respondents a door to door survey was made to locate the specific address and/or resident of each sampled person. It was initially difficult to gain access to those sampled elderly persons owing to their special fears of crime or exploitation. A few of our study participants expressed concern that their responses to our questions/interview may create misunderstanding within the family. However, such difficulties have been over cum with the help and cooperation of the local Club and /or ward members.

Data on economic resources of the individual respondent have been collected by interview technique with the help of structured questionnaire schedules.

The primary data has been analyzed through percentages calculation on the basis of odd prime number using the Microsoft excel sheet.

\section{RESULTS AND DISCUSSION}

Table 1 exhibits that in case of 'Sources of Financial
Support' $36.40 \%$ of the total number of the respondents are financially dependent respectively on different types of pension and $17.20 \%$ of the total number of the respondents are dependent respectively on their married sons, $7.60 \%$ dependent on unmarried sons, $6.60 \%$ dependent on married daughter, $3.60 \%$ dependent on unmarried daughter and $7.20 \%$ respondents are dependent their spouse or husbands. It is further revealed from this table that $3.60 \%$ of the total number of the respondents are dependent on their savings interest, $2.80 \%$ of the total number of the respondents are dependent on house rent sources and depend on $6.40 \%$ their respective relatives other than spouse and children, whereas $8.60 \%$ of the total number of the respondents financially depend on the profits earned respectively from their own small scale retail shop.

Moreover, the data also indicates that after completing 80 years and above ages a major portion of urban female oldest old respondents are economically dependent on pension where few respondents are economically dependent on their respective children. Thus refers that somehow the responsibility and care depends on finance condition where relationship does not matter.

The Table 1 also reveals that in case of 'Sources of Pension' $21.98 \%$ of the total number of the respondents receive pension due to the death of their spouses who were in the Govt. services and $14.84 \%$ of the total number of the respondents receive their own pension after their retirement from the Govt. services. However, in some cases same person is receiving pension for both the said two reasons and therefore she has been simultaneously included respectively in both the two categories namely 'Own Pension after retirement from Govt. Services' and 'Govt. Pension of respective spouses after their death'. The table also depicts that $39.56 \%$ of the total number of the respondents receive 'Widow Pension' and $23.63 \%$ receive 'Old Age Pension'. It may be mentioned in this context that said two types of pension are under the scheme of the Ministry of Social Justice and Empowerment, Govt. of India.

It is pertinent to mention here that in number of cases it is found that a single respondent is financially dependent simultaneously on two or more than two sources. Therefore, they have been included simultaneously in more than one 
category under the heading of 'Sources of Financial Support'. Thus, the sum total number of respondents mentioned under the heading of 'Sources of Financial Support' in Table 1 exceeds the actual number of respondents sampled for the purpose of the present study.

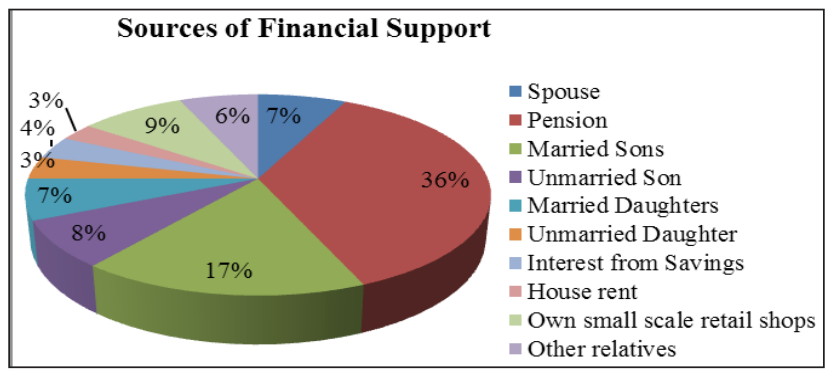

Fig. 1: Pie-chart shows the Sources of Financial Support

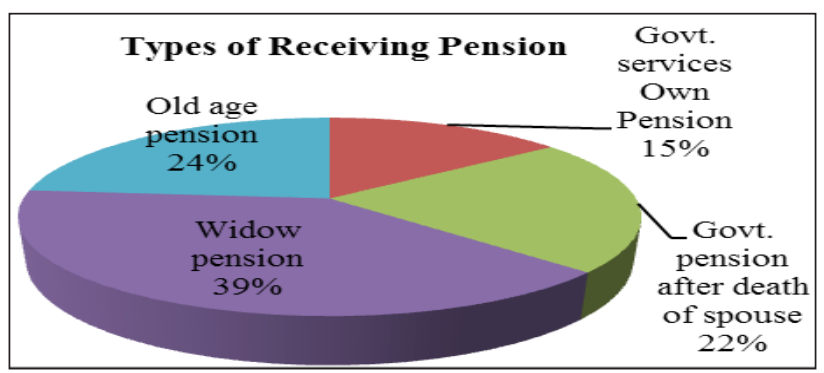

Fig. 2: Pie-chart shows the types of Receiving Pension

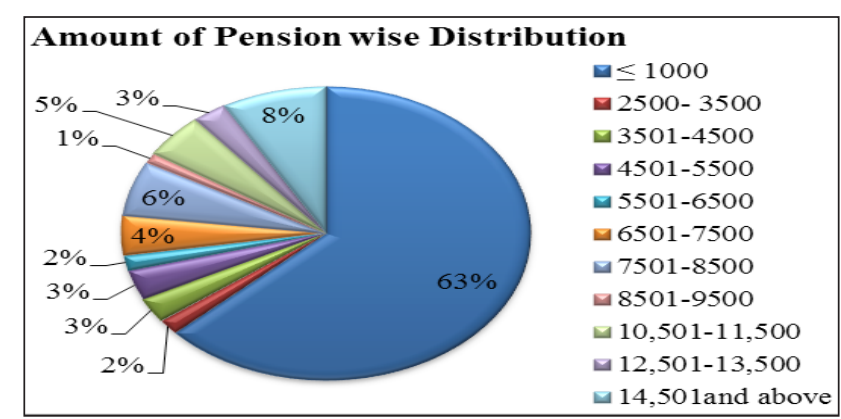

Fig. 3: Pie-chart shows the Amount of Receiving Pension

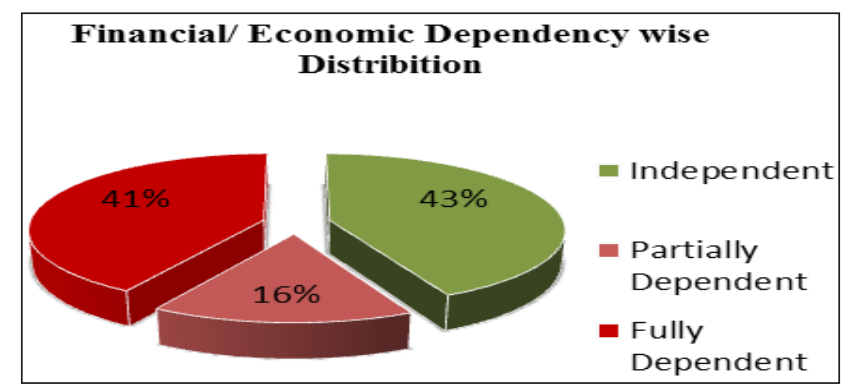

Fig. 4: Pie-chart shows the Financial/ Economic Dependency

It appears from the Table 1 that about $63.19 \%$ of the total number of the respondents receives less than
₹ 1000 per month either as old-age pension or as widow pension sanctioned by the Ministry of Social Justice and Empowerment, Govt. of India.

Table 1: Economic resources of the respondents

\begin{tabular}{|c|c|c|}
\hline Variables & $\begin{array}{l}\text { No. of } \\
\text { Persons } \\
\text { (N) }\end{array}$ & $\begin{array}{l}\text { Percentage } \\
(\%)\end{array}$ \\
\hline \multicolumn{3}{|l|}{ Sources of Financial Support: } \\
\hline Spouse & 36 & 7.20 \\
\hline Pension & 182 & 36.40 \\
\hline Married Sons & 86 & 17.20 \\
\hline Unmarried Son & 38 & 7.60 \\
\hline Married Daughters & 33 & 6.60 \\
\hline Unmarried Daughter & 18 & 3.60 \\
\hline Interest from Savings & 18 & 3.60 \\
\hline House rent & 14 & 2.80 \\
\hline Own Retail shops & 43 & 8.60 \\
\hline Other relatives & 32 & 6.40 \\
\hline \multicolumn{3}{|l|}{ Sources of Pension } \\
\hline Govt. services Own Pension & 27 & 14.84 \\
\hline $\begin{array}{l}\text { Govt. pension after death of } \\
\text { spouse }\end{array}$ & 40 & 21.98 \\
\hline Widow pension & 72 & 39.56 \\
\hline Old age pension & 43 & 23.63 \\
\hline \multicolumn{3}{|l|}{ Amount of Pension (in ₹) } \\
\hline$\leq 1000$ & 115 & 63.19 \\
\hline $2500-3500$ & 3 & 1.65 \\
\hline $3501-4500$ & 5 & 2.75 \\
\hline $4501-5500$ & 6 & 3.30 \\
\hline $5501-6500$ & 3 & 1.65 \\
\hline $6501-7500$ & 8 & 4.40 \\
\hline $7501-8500$ & 11 & 6.04 \\
\hline $8501-9500$ & 2 & 1.10 \\
\hline $10,501-11,500$ & 9 & 4.95 \\
\hline $12,501-13,500$ & 5 & 2.75 \\
\hline 14,501 and above & 15 & 8.24 \\
\hline \multicolumn{3}{|c|}{ Financial/ Economic Dependency } \\
\hline Independent & 214 & 42.8 \\
\hline Partially Dependent & 79 & 15.8 \\
\hline Fully Dependent & 207 & 41.4 \\
\hline
\end{tabular}

It is revealed from the Table 1 that in case of postretirement monthly service pension the amount ranging from $₹ 2500$ to $₹ 3500$ is received by $1.65 \%$ of the total number of the respondents similarly ₹ 5501 to ₹ 6500 received by $1.65 \%$; 3501 to ₹ 4500 is received by $2.75 \%$ of the total number of the respondents; ₹ 4501 to ₹ 5500 received by $3.30 \%$ 
of the total number of the respondents; ₹ 6501 to ₹ 7500 received by $4.40 \%$ of the total number of the respondents; ₹ 7501 to ₹ 8500 received by $6.04 \%$ of the total number of the respondents; ₹ 8501 to ₹ 9500 received by $1.10 \%$ of the total number of the respondents; ₹ 10,501 to ₹ 11,500 received by $4.95 \%$ of the total number of the respondents; ₹ 12,501 to ₹ 13,500 received by $2.75 \%$ of the total number of the respondents; ₹ 14, 501 and above received by $8.24 \%$ of the total number of the respondents.

The Table 1 furthermore exposes that in case of 'Economic Dependency' $42.8 \%$ of the total number of the respondents has been economically independent whereas, $15.8 \%$ respondents has been economically partially independent and $41.8 \%$ of the total number of the respondents has been economically dependent.

The data on financial and or economic dependency collected on the self-perception on individual and all of the respondents have been select their dependency on income sources. Therefore, the respondents who has been getting the various types of pension those respondents and who get interest from savings amount those respondents were completely financially independent as they stated; whereas, those respondents who were dependent on husband/ spouses sources of income and own small retail shop those respondents were partially financial dependent as they stated; but who economically depend on their respective children those respondents were fully financial dependent as they stated.

\section{ACKNOWLEDGEMENTS}

We express my deep senses of gratitude to those oldest old people residing under Medinipur Municipal Town in the district of Pashim Medinipur for their co-operation in all possible ways to carry out the field work related to the present dissertation. To all we iterate our apology for perturbing their tranquil life which demands peace and rest.

We also grateful to Professor Manoranjan Pal, Economic Research Unit, Indian Statistical Institute who spent his valuable time by way of supervising the sampling, data coding \& analyzing the data.

Finally, we remain thankful to the University Grants Commission of India (UGC India) who was the funding authority for this research work.

\section{CONCLUSION}

Anthropology has much to offer study on elderly populations. However, this study provides economic resources among the oldest old female residing in Medinipur Municipal town in West Bengal who is likely to need assistance from programmes organized by the Government both at the State as well as at Central level.

Moreover, even among the respondent pensioners about $64 \%$ of the total number of the respondents receive pension below ₹ 1000 per month among whom $39.56 \%$ were widow pension holder and $23.63 \%$ were old age pension holder. It is found that about $35 \%$ of the oldest old female population of urban areas under Paschim Medinipur district dependent on their respective children for economically support. However, this fact may be considered as the presence of thin family bondage between the oldest old female and their children. In above view the study concluded vulnerability portrait as economic sources among the urban oldest old people through an anthropological vision.

Finally, the present study may be helpful to raise the different issues like social dimension of aging in urban areas, effective of aging in later life, economic problems of aging in urban areas and others in aged study especially in gerontological as well as anthropological study for further researches.

\section{REFERENCES}

Baltes, M.M., Mayr, U., Borchelt, M., Maas, I. and Wilms, H.U. 1993. Everyday Competence in old and very old age: An inter-disciplinary perspective. Ageing and Society, 13: $657-680$.

Biswas, S.K. 1985. Dependency and Family Care of the Aged in Village India: A Case Study. Journal of the Indian Anthropological Society, 20(3): 238 - 257.

Bose A.B. and Saxena, P.C. 1964. Some Characteristics of the Aged Population in Rural Society. The Journal of Family Welfare, 10(4): $33-39$.

Chakrabarty, F. 2003. Contributions of the Elderly in an Agrarian Setting in Rural West Bengal: Perspective on Policy. J. Indian Anthrop. Soc., 38: 349-354.

Chakraborty Parikshit and Chakrabarty Falguni 2017. "Socio-Demographic Setup of the Rural Oldest Old: An Anthropological Assessment". Journal of Scholars Academic and Scientific Publishers (SAS Publishers).

Chakraborty Parikshit and Chakrabarty Falguni, 2017. "Activities of Daily Living (ADL) among the Rural Oldest Old People: A study in Paschim Medinipur District of West 
Bengal, India". Journal of the Department of Anthropology, University of Calcutta.

Chakraborty Parikshit 2018. "Activities of Daily Living among the Oldest-old People: A Rural Urban Study" Journal of Advanced Research in Humanities and Social Science, 5(1): 1-4.

Coale, Ansley J. and Ellen Eliason Kisker 1986. “Mortality Crossovers: Reality or bad data?" Population Studies, 40(3): $389-401$.

Dak, T.M. and Sharma, M.L. 1987. Changing Status of the Aged in North Indian Villages. In: Aging in India: Challenge for the Society, ed. By M.L. Sharma and T.M. Dak, pp. 43 - 55. Ajanta Publications. New Delhi.

Donahue, W. 1960. Trends in social gerontology. Geriatrics, 15: 801.

Elo, Irma T. and Samuel H. Preston. 1994. Estimating AfricanAmerican Mortality from Inaccurate Data, Demography, 31(3): 427-458.

ENS Economic Bureau. (March 01, 2011). In India growing young, a special tax break to the 'super senior' 80-plus. The Indian Express. New Delhi.

Grundy, Emily, Ann Bowling, and Morag Farquhar. 1996. Social Support, Life Satisfaction and Survival at Older ages, in Health and Mortality Among Elderly Populations, ed. Graziella Caselli and Alan D. Lopez. Oxford: Clarendon Press, pp. $135-156$.

Karkal, Malini 2000. Elderly in India: An Annotated Bibliography in Searches of Answers in the Year of Older Persons - 1999, Vols. I and II. Tata Institute of Social Sciences, Bombay.

Khan, M.Z. 1997. Elderly in Metropolis. New Delhi: Inter-India Publications, pp. 138-170.
Mosley, W.H. and Gray, R. 1993. Childhood Precursors of Adult Morbidity and Mortality in Developing Countries: Implications for Health Programs, in The Epidemiological Transition: Policy and Planning Implications for Developing Countries, ed. James N. Gribble and Samuel H. Preston. Washington, DC: National Academy Press, pp. 69-100.

Neugarten, B.L. 1974. Age groups in American society and the rise of the young-old. The Annals of the American Academy of Political and Social Science, 415: 187-198.

Rajan, Irudaya, S., Mishra, U.S. and Sarma, P.S. 1999. “India's Elderly: Burden or Challenge"? Sage Publications, New Delhi.

Registrar General and Census of India, 2006. 'Population Projections for India and States, 2001-2026, Report of The Technical Group on Population Projections Constituted by the National Commission on Population, New Delhi.

Singh, K., Singh, R. and Sharma, M.L. 1987. "Problems of aged women in Haryana"; In M.L. Sharma \& T.M. Dak (Eds.), Aging in India (pp. 134-144). New Delhi, India: Ajanta Publications.

Suzman, R.M. and Riley, M.W. 1985. Introducing the "oldest old." Milbank Memorial Fund Quarterly, 63: 177 - 186.

Suzman, R.M., Willis, D.P. and Manton, K.G., Eds. 1992. The oldest old. New York: Oxford University Press.

UNDP, 2001. Human Development Report, Delhi: Oxford University Press.

Vaupel, J.W. et al. 1998. Biodemographic trajectories of longevity, Science, 280(5365): $855-860$.

Yi, Zeng., Vaupel, James W., Zhenyu, X. and Yuzhi, L. 2002. Population and Development Review, 28(2): 251 - 273. 